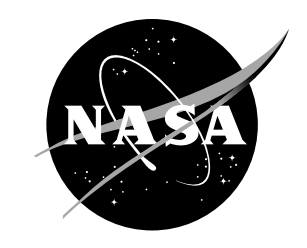

\title{
Modeling Progressive Damage Using Local Displacement Discontinuities Within the FEAMAC Multiscale Modeling Framework
}

\author{
Vipul Ranatunga \\ Miami University, Middletown, Ohio \\ Brett A. Bednarcyk and Steven M. Arnold \\ Glenn Research Center, Cleveland, Ohio
}




\section{NASA STI Program . . . in Profile}

Since its founding, NASA has been dedicated to the advancement of aeronautics and space science. The NASA Scientific and Technical Information (STI) program plays a key part in helping NASA maintain this important role.

The NASA STI Program operates under the auspices of the Agency Chief Information Officer. It collects, organizes, provides for archiving, and disseminates NASA's STI. The NASA STI program provides access to the NASA Aeronautics and Space Database and its public interface, the NASA Technical Reports Server, thus providing one of the largest collections of aeronautical and space science STI in the world. Results are published in both non-NASA channels and by NASA in the NASA STI Report Series, which includes the following report types:

- TECHNICAL PUBLICATION. Reports of completed research or a major significant phase of research that present the results of NASA programs and include extensive data or theoretical analysis. Includes compilations of significant scientific and technical data and information deemed to be of continuing reference value. NASA counterpart of peer-reviewed formal professional papers but has less stringent limitations on manuscript length and extent of graphic presentations.

- TECHNICAL MEMORANDUM. Scientific and technical findings that are preliminary or of specialized interest, e.g., quick release reports, working papers, and bibliographies that contain minimal annotation. Does not contain extensive analysis.

- CONTRACTOR REPORT. Scientific and technical findings by NASA-sponsored contractors and grantees.
- CONFERENCE PUBLICATION. Collected papers from scientific and technical conferences, symposia, seminars, or other meetings sponsored or cosponsored by NASA.

- SPECIAL PUBLICATION. Scientific, technical, or historical information from NASA programs, projects, and missions, often concerned with subjects having substantial public interest.

- TECHNICAL TRANSLATION. Englishlanguage translations of foreign scientific and technical material pertinent to NASA's mission.

Specialized services also include creating custom thesauri, building customized databases, organizing and publishing research results.

For more information about the NASA STI program, see the following:

- Access the NASA STI program home page at http://www.sti.nasa.gov

- E-mail your question via the Internet to help@ sti.nasa.gov

- Fax your question to the NASA STI Help Desk at 443-757-5803

- Telephone the NASA STI Help Desk at 443-757-5802

- Write to: NASA Center for AeroSpace Information (CASI) 7115 Standard Drive Hanover, MD 21076-1320 


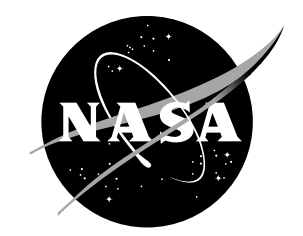

\section{Modeling Progressive Damage Using Local Displacement Discontinuities Within the FEAMAC Multiscale Modeling Framework}

Vipul Ranatunga

Miami University, Middletown, Ohio

Brett A. Bednarcyk and Steven M. Arnold

Glenn Research Center, Cleveland, Ohio

Prepared for the

51st Structures, Structural Dynamics, and Materials Conference cosponsored by AIAA, ASME, ASCE, AHS, and ASC

Orlando, Florida, April 12-15, 2010

National Aeronautics and

Space Administration

Glenn Research Center

Cleveland, Ohio 44135 


\section{Acknowledgments}

The first author would like to recognize the support received through the NASA Summer Faculty Fellowship Program, supported by the Exploration Technology Development Program (ETDP) Advanced Composites Technologies (ACT)

Project and the software and hardware resources utilized for this research from the Research Computing Support Group at Miami University.

Level of Review: This material has been technically reviewed by technical management.

Available from

NASA Center for Aerospace Information 7115 Standard Drive

Hanover, MD 21076-1320
National Technical Information Service 5301 Shawnee Road Alexandria, VA 22312

Available electronically at http://gltrs.grc.nasa.gov 


\title{
Modeling Progressive Damage Using Local Displacement Discontinuities Within the FEAMAC Multiscale Modeling Framework
}

\author{
Vipul Ranatunga \\ Miami University \\ Middletown, Ohio 45042 \\ Brett A. Bednarcyk and Steven M. Arnold \\ National Aeronautics and Space Administration \\ Glenn Research Center \\ Cleveland, Ohio 44135
}

\begin{abstract}
A method for performing progressive damage modeling in composite materials and structures based on continuum level interfacial displacement discontinuities is presented. The proposed method enables the exponential evolution of the interfacial compliance, resulting in unloading of the tractions at the interface after delamination or failure occurs. In this paper, the proposed continuum displacement discontinuity model has been used to simulate failure within both isotropic and orthotropic materials efficiently and to explore the possibility of predicting the crack path, therein. Simulation results obtained from Mode-I and Mode-II fracture compare the proposed approach with the cohesive element approach and Virtual Crack Closure Techniques (VCCT) available within the ABAQUS (ABAQUS, Inc.) finite element software. Furthermore, an eccentrically loaded 3-point bend test has been simulated with the displacement discontinuity model, and the resulting crack path prediction has been compared with a prediction based on the extended finite element model (XFEM) approach.
\end{abstract}

\section{Introduction}

Carbon fiber-reinforced polymers (CFRPs) are used widely for many applications including aircraft, automotive, and civil structures. Some of the appealing properties of CFRPs include high specific strength and stiffness, corrosion resistance, fatigue resistance, and suitability for stealth applications. Increased usage of CFRPs in the future depends on the development of damage-tolerant composite structures while lowering the cost of manufacturing. One of the issues with CFRPs for structural applications is the joining of sections made with fiberreinforced composites. Among other joining methods in current practice, two of the most popular methods are adhesive bonding and mechanical fastening where the mechanical fastening is preferred for thicker sections while adhesive bonding is used for thinner sections. Delamination is a major type of failure associated with adhesivelybonded composite joints.

In the past, failure of composites has been investigated extensively from the micromechanical and macromechanical points of view. On the micromechanical scale, failure mechanisms are related to the properties of the constituent phases, i.e., matrix, reinforcement, and the interface. This paper will investigate the advantages and disadvantages of modeling damage propagation in materials utilizing a displacement discontinuity approach. The displacement discontinuity approach known as ECI (evolving compliant interface) (Refs. 1 and 2) enables exponential evolution of the interfacial compliance, resulting in unloading of the tractions at the interface after failure/delaminations occurs. The current study utilizes the implementation of this approach available within NASA's FEAMAC (Ref. 3) multiscale micromechanics analysis framework. Given the fact that the commercially available techniques such as VCCT (Ref. 4) and cohesive element (Ref. 5) approaches require a priori knowledge of the crack path, and as discussed elsewhere (Ref. 6), the current implementation of these approaches present difficulties with numerical convergence, forcing one to deal with a number of parameters to overcome these convergence issues. Therefore, in this paper, a computationally-efficient multiscale modeling framework is presented, and the propagation of damage is investigated utilizing this framework in the context of finite element method. The future intent is to apply this approach to the failure/delaminations of composite structures.

To begin the investigation, VCCT and cohesive element approaches are used to model self-similar cracks in double cantilever beam (DCB) the end-notched flexure (ENF) tests, and the results are compared with FEAMAC predictions. Once the material data and the simulation-specific parameters have been identified through these preliminary simulations, the focus shifts to an eccentrically-loaded three-point bend test. In the absence of 
experimental data to validate the FEAMAC prediction for the crack path, the extended finite element method (XFEM) (Ref. 7) available in the Abaqus finite element package is utilized for comparison purposes. The study concludes with highlighting the advantages and disadvantages of the FEAMAC and XFEM approaches.

\section{Displacement Discontinuity Approach and the Evolving Compliance Interface Model}

The displacement discontinuity approach employed herein follows the basic form proposed by Jones and Whittier (Ref. 8), in which a debonded interface is modeled by imposing a discontinuity (i.e., "jump") in a given displacement component across the interface. This basic form can be written,

$$
\left[u_{j}\right]^{I}=\left.R_{j} \sigma_{j}\right|^{I}
$$

Where $\left[u_{j}\right]^{I}$ is the discontinuity in displacement component $j$ at interface $I, \sigma_{j}$ is the corresponding stress component at interface $I$, and $R_{j}$ is a proportionality constant that may be thought of as a flexibility for the interface (as it relates the interfacial displacement jump to the interfacial stress). This flexible interface model has been applied extensively to model fiber-matrix interfacial debonding in composite materials. It was incorporated within the method of cells micromechanics model by Aboudi (Ref. 9) and within the generalized method of cell by Sankurathri et al. (Ref. 10). Achenbach and Zhu (Ref. 11) added the condition to this flexible interface model that, when in compression, the interface must behave as if well-bonded (i.e., $R_{j}=0$ ). Wilt and Arnold (Ref. 12) added finite bond strength to the interface, $\left.\sigma_{D B}^{j}\right|^{I}$, such that the interface behaves as perfectly bonded until the interfacial stress reaches this interfacial strength. Bednarcyk and Arnold (Refs. 1 and 2) further extended the Jones and Whittier (Ref. 8) flexible interface model to admit time dependence in the $R_{j}$ parameter. By allowing this parameter to evolve with time, it is possible to enable unloading and redistribution of the interfacial stress upon initiation of debonding or delamination. Considering the components normal $(n)$ and tangential $(t)$ to a particular interface separately, the equations for the displacement discontinuity components can be written as,

$$
\begin{array}{ll}
{\left[u_{n}\right]^{I}=\left.R_{n}(t) \sigma_{n}\right|^{I} ;} & \left.\sigma_{n}\right|^{I} \geq\left.\sigma_{D B}^{n}\right|^{I} \\
{\left[u_{t}\right]^{I}=\left.R_{t}(t) \sigma_{t}\right|^{I} ;} & \left.\sigma_{t}\right|^{I} \geq\left.\sigma_{D B}^{t}\right|^{I}
\end{array}
$$

where the time-dependence of the $R_{j}$ parameter, as well as the finite bond strength of the interface, has been denoted. This form of the Jones and Whittier (Ref. 8) flexible interface model has been called the evolving compliant interface (ECI) model in order to distinguish it from the previous form that incorporates a constant value for the $R_{j}$ parameter.

Many forms for the time-dependence of the $R_{j}$ parameter, both implicit and explicit, were examined by Bednarcyk and Arnold (Ref. 1). It was determined that explicit exponential time-dependence provides the model with the desired ability to unload interfacial stress, permitting redistribution of this stress. Further, the ECI model compares well (in a qualitative sense) with several previous interfacial constitutive models that incorporate interfacial stress unloading, e.g., Needleman (Ref. 13). The ECI model representation of the debonding parameter put forth by Bednarcyk and Arnold (Refs. 1 and 2) is,

$$
R_{j}(t)=\Lambda_{j}\left[\exp \left(\frac{t-t_{D B}}{\mathrm{~B}_{j}}\right)-1\right] \quad t \geq t_{D B}
$$

where $t_{D B}$ is the time at which debonding occurs (for the particular interface), and $\Lambda_{j}$ and $\mathrm{B}_{j}$ are parameters that characterize the interfacial time-dependent behavior. The typical effective interfacial behavior represented by the ECI model is plotted in Figure 1. Until the interfacial stress reaches the bond strength $\left(\sigma_{D B}\right)$, the interfacial displacement is zero. Then, debonding occurs and the interfacial stress rises and then falls as the interface opens. 


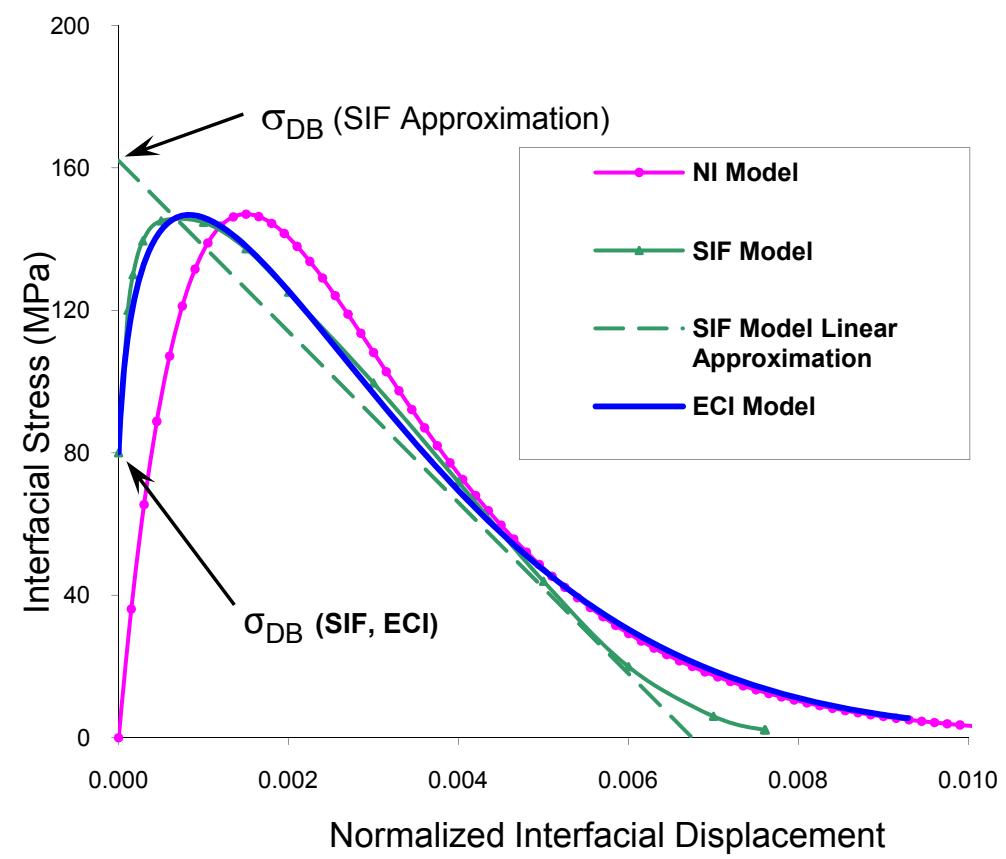

Figure 1.-Comparison of the ECl model with the Needleman (Ref. 13) interface (NI) model and the statistical interfacial failure (SIF) model developed by Robertson and Mall (Ref. 14).

Also presented in Figure 1 is a comparison of the ECI model with two previous interfacial constitutive models that also admit unloading of the interfacial stress. The well-known model of Needleman (Ref. 13) (NI model) is one such interfacial representation. While this model does not incorporate finite bond strength, the effective interfacial behavior is qualitatively similar to that of the ECI model. The fact that the NI model equations are explicitly nonlinear in their relation between interfacial tractions and interfacial displacements, can add difficulty to the global solution when incorporated within micromechanics models. Further, the effective interfacial response of the statistical interfacial failure (SIF) model, developed by Robertson and Mall (Ref. 14), is plotted in Figure 1 as well. Its qualitative similarity to the ECI model and NI model is obvious. Since the SIF model, like the NI model, is nonlinear, Robertson and Mall (Ref. 14) incorporated a linear approximation of the SIF model (also plotted in Fig. 1) within their employed micromechanics model (the method of cells).

The displacement discontinuity approach with evolving compliance interface (ECI) model available within NASA's FEAMAC micromechanics analysis framework is primarily developed for modeling debonding between fiber and matrix materials. The FEAMAC framework and the ECI model are employed in the present investigation to examine crack propagation in the context of finite element simulations. Detailed comparisons of the FEAMAC predictions against finite element-based VCCT and cohesive element predictions under Mode-I and Mode-II are discussed and the advantages and disadvantages of each technique are discussed in the subsequent sections. Prediction of the crack path by FEAMAC is compared with XFEM predictions in the absence of experimental data.

\section{A. Simulations With a DCB Specimen}

\section{Results}

The double cantilever beam test has widely been used for obtaining Mode-I interlaminar fracture toughness in composite materials. The test uses a geometry shown in Figure 2 with an initial delamination crack and the delamination is forced to grow by pulling apart the two plies of the specimen. To begin the comparison between the FEAMAC, VCCT, and the cohesive element approaches, a transversely-isotropic material and the geometry shown in Figure 2 is considered. The selected beam geometry has a length (L) of 4 in., width (2W) of 0.12 in. and thickness of $0.3 \mathrm{in}$. as used by Song et al. (Ref. 15). The beam includes two sub-laminates, each with a thickness of $0.06 \mathrm{in}$. and an initial crack length $\left(\mathrm{C}_{\mathrm{L}}\right)$ of $1.15 \mathrm{in}$. between the two sub-laminates. Material properties of AS4/3501-6 (Ref. 15) given in Table 1 are used in the plane-strain finite element models, considering unidirectional fibers aligned with the length direction (Y) of the specimen. 


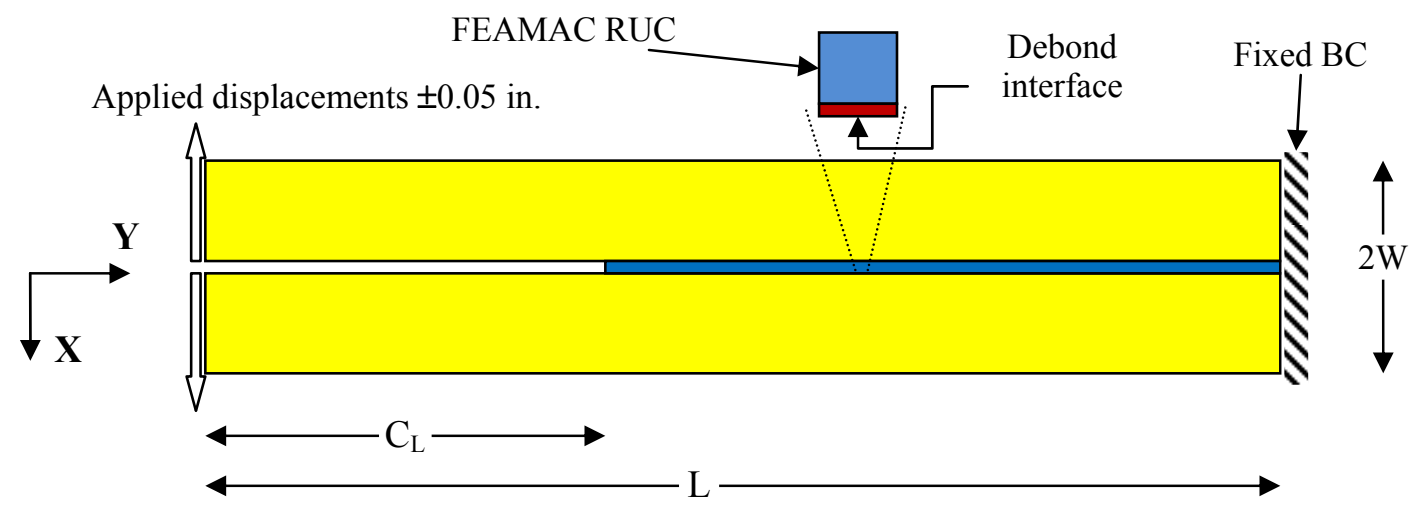

Figure 2.-Geometry of the DCB specimen with applied boundary conditions.

TABLE 1.-MECHANICAL PROPERTIES OF AS4/3501-6 INCLUDING PARAMETERS USED WITH TRACTION-SEPARATION BASED COHESIVE ELEMENT SIMULATIONS (REF. 15)

\begin{tabular}{|c|c|c|c|c|c|}
\hline $\mathrm{E}_{1} / \mathrm{ksi}$ & $\mathrm{E}_{2} / \mathrm{ksi}$ & $\mathrm{E}_{3} / \mathrm{ksi}$ & $\mathrm{G}_{12} / \mathrm{ksi}$ & $\mathrm{G}_{13} / \mathrm{ksi}$ & $\mathrm{G}_{23} / \mathrm{ksi}$ \\
\hline 21,500 & 1640 & 1640 & 871 & 871 & 522 \\
\hline$v_{12}=v_{13}$ & $v_{23}$ & $\mathrm{G}_{\mathrm{IC}}$ /in.-lb/in. ${ }^{2}$ & $\mathrm{G}_{\mathrm{IIC}} /$ in. $\mathrm{lb} /$ in. $^{2}$ & $\mathrm{G}_{\mathrm{IIIC}} /$ in.-lb/in. $^{2}$ & $\eta$ \\
\hline 0.30 & 0.45 & 0.486 & 3.17 & 3.17 & 1.8 \\
\hline$\sigma_{n}^{0} / \mathrm{psi}$ & $\sigma_{s}^{0} / \mathrm{psi}$ & $\sigma_{t}^{0} / \mathrm{psi}$ & $\mathrm{K}_{1} / \mathrm{psi}$ & $\mathrm{K}_{2} / \mathrm{psi}$ & $\mathrm{K}_{3} / \mathrm{psi}$ \\
\hline 7800 & 12600 & 12600 & $1.37 \mathrm{e} 9$ & $1.37 \mathrm{e} 9$ & $1.37 \mathrm{e} 9$ \\
\hline
\end{tabular}

The middle strip of elements shown in blue in Figure 2 in the case of the FEAMAC simulations, are represented with a FEAMAC micromechanics repeating unit cell (RUC) through an ABAQUS user material. Usually such an RUC consists of a number of subcells and is used to represent a composite material. However, for these DCB simulations, the material is treated as homogenized and transversely isotropic, so the RUC consists of a single graphite/epoxy subcell with $\mathrm{X}-\mathrm{Z}$ plane of isotropy, and interfacial debonding activated at the RUC interface as indicated in Figure 2. The same elastic transversely-isotropic graphite/epoxy material properties are used within the single-subcell FEAMAC RUC. It should be noted that FEAMAC enforces periodicity conditions at the RUC boundaries, thus the shown RUC represents a material that is continuous in the Y-direction, even though an interfacial displacement discontinuity, according to the ECI model described above, is enabled in the X-direction. The remainder of the geometry (yellow) is meshed using bilinear incompatible-mode plane strain (CPE4I) elements with elastic orthotropic material model with transverse isotropy as given in Table 1.

In the case of simulations utilizing the ABAQUS cohesive and VCCT approaches, the geometry shown in Figure 2 remains the same with the exception of the introduction of a surface between the two plies. For simulations with the cohesive approach, cohesive surface elements are employed to discretize this surface between the two plies, whereas simulations utilizing the VCCT approach, this surface between the two plies is defined as the possible crack path. In both approaches, same crack length of $\mathrm{C}_{\mathrm{L}}$ is maintained and the remainder of the model is meshed using bilinear incompatible-mode plane strain (CPE4I) elements with the standard ABAQUS elastic orthotropic model with transverse isotropy, representing the same graphite/epoxy material discussed above.

\section{B. Comparison of VCCT, Cohesive, and FEAMAC predictions for DCB Test}

A comparison of reaction forces predicted by the FEAMAC approach, VCCT approach, and cohesive surface approach is shown in Figure 3. In the case of VCCT simulation, debonding is determined entirely by the critical strain energy release rate $\mathrm{G}_{\mathrm{IC}}$ reported in Table 1 . For cohesive surface approach, normal debond strength $\sigma_{n}^{0}$ as well 


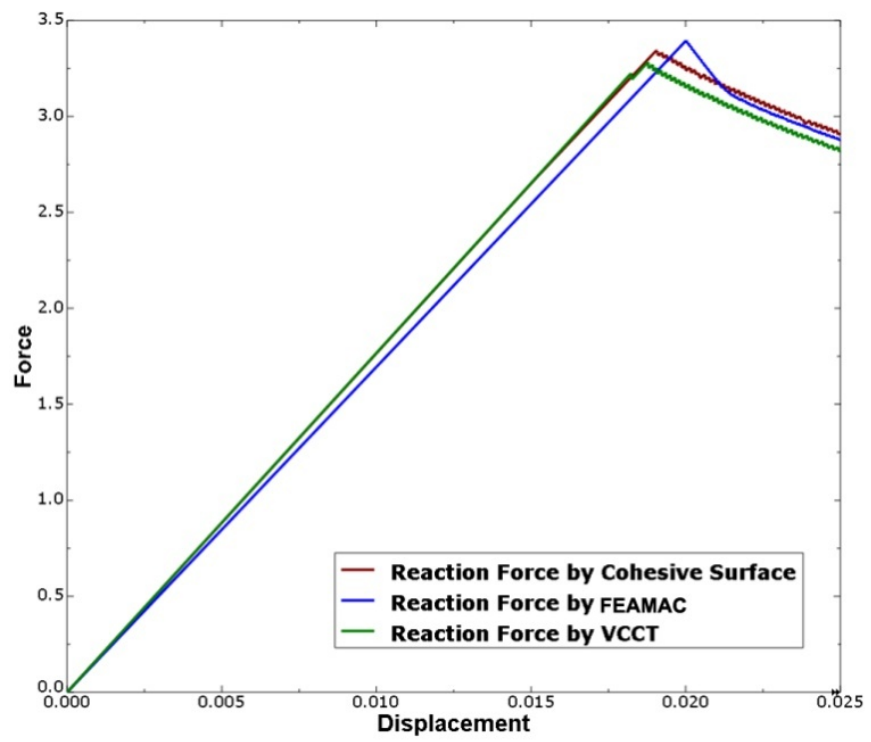

Figure 3.-Reaction forces predicted by VCCT, cohesive, and FEAMAC using adjusted $\mathrm{G}_{\mathrm{c}}$ and $\sigma_{n}^{0}$ for $\mathrm{DCB}$.

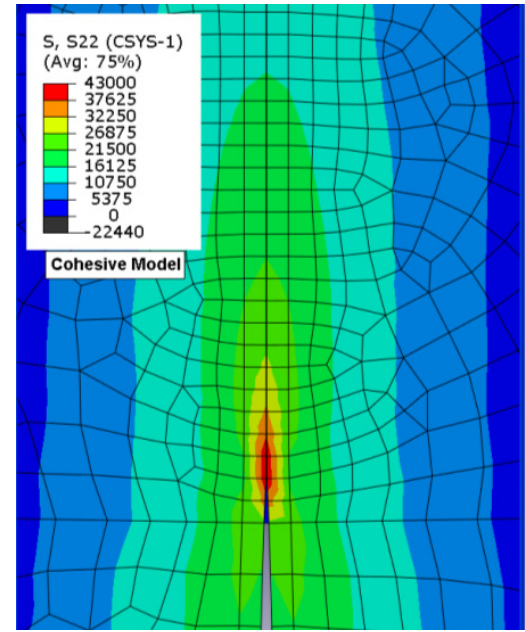

a) Cohesive Model

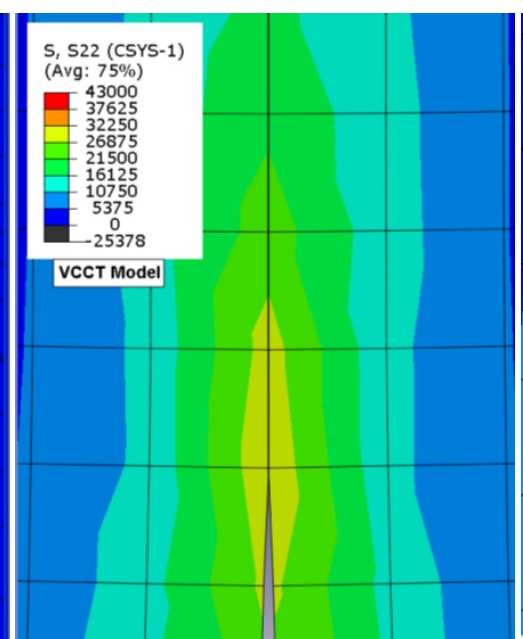

b) VCCT Model

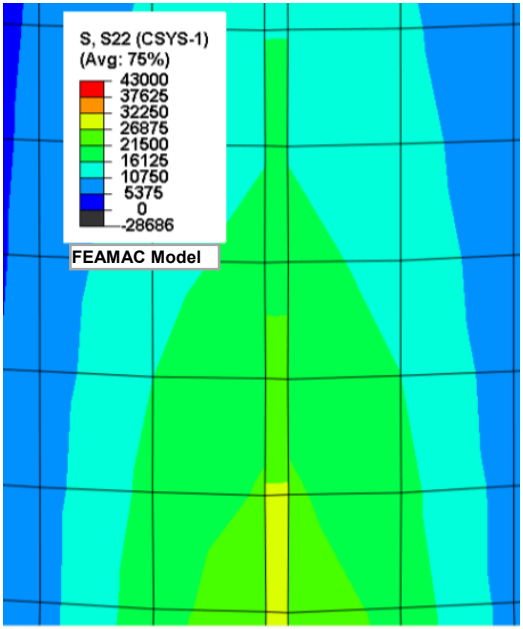

c) FEAMAC Model

Figure 4.-Comparison of stress component along the fiber (vertical) direction for cohesive, VCCT, and FEAMAC models at the beginning of crack propagation for a similar width of the geometry.

as $\mathrm{G}_{\mathrm{IC}}$ have been used to determine the crack initiation and propagation, respectively. For the FEAMAC approach, this same debond strength $\sigma_{n}^{0}$ is used for the bond strength $\sigma_{D B}^{n}$ parameter as expressed in Equation (2). In addition to the $\sigma_{D B}^{n}$, two other parameters critical to interfacial time-dependent behavior of the ECI model are the $\Lambda_{i}$ and $B_{j}$ as reported in Equation (4). To create an interfacial debonding behavior similar to the cohesive and VCCT approaches, a value of 0.1 is selected for $\Lambda_{i}$ and 3.0 is selected for the parameter $B_{j}$.

The stress distributions for these three models along the crack front are shown in Figure 4. As expected with the denser cohesive mesh, the local stress distribution near the crack-tip is relatively high compared to the VCCT and FEAMAC DCB models. Both VCCT and FEAMAC models use the same element size of 0.01 in. over the entire length of the beam. Regardless of the disagreement of local peak stresses near the crack-tip, the overall stress distribution shows similarity while the overall response of these three models remain consistant as evidenced from reaction forces shown in Figure 3. 
TABLE 2.-TOTAL CPU TIME TAKE FOR COMPLETING

A SIMULATION WITH FEAMAC, VCCT, AND COHESIVE MODELS

\begin{tabular}{|l|c|}
\hline \multicolumn{1}{|c|}{ Model } & Total CPU Time/s \\
\hline FEAMAC Model & 1423 \\
\hline VCCT Model & 3241 \\
\hline Cohesive Model & 14,806 \\
\hline
\end{tabular}

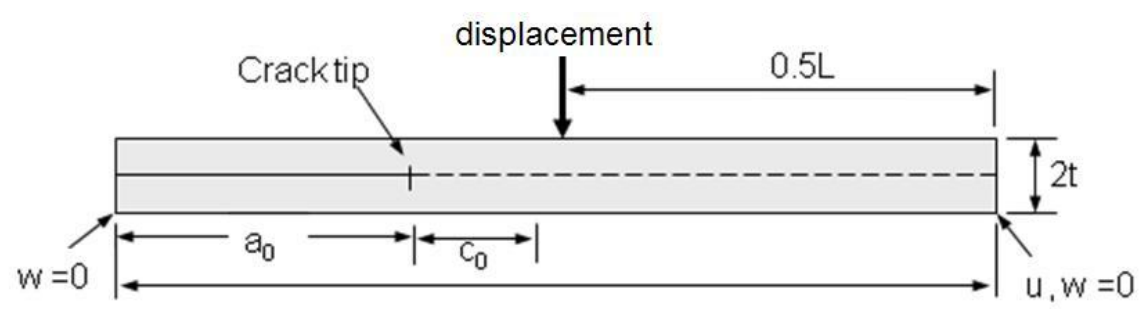

Figure 5.-Geometry of the ENF specimen with applied boundary conditions (Ref. 15).

The time taken to complete the execution of each model is shown in Table 2. Clearly, a significant execution time advantage is achieved when employing the FEAMAC approach over the VCCT and cohesive approaches. The DCB model with cohesive elements having a maximum allowable time of $0.01 \mathrm{sec}$, took approximately ten times more CPU time as compared to the FEAMAC simulation with a $0.075 \mathrm{sec}$ constant time increment. If a larger maximum allowable time increment is used for the cohesive model, the solution process becomes unstable due to severe nonlinearities at the verge of the crack initiation. Abaqus/Standard offers a set of stabilization mechanisms to handle nonlinear problems by allowing the user to specify a number of solution control parameters such as number of equilibrium iterations $\left(I_{0}\right)$ and number of equilibrium iterations after which the logarithmic rate of convergence check begins $\left(I_{R}\right)$. Even with the current increment of $0.01 \mathrm{sec}$ for the cohesive model, these convergence parameters had to be modified in order to stabilize the solution process.

\section{Simulations With an End-Notched Flexure Specimen}

The three-point end-notched flexure (ENF) test has been used to obtain the fracture toughness in Mode-II type delaminations where the initial crack is forced to grow by shearing. The dimensions and geometry used for ENF simulations is same as the DCB simulations, except for the applied boundary conditions (see Fig. 5), wherein one end is pinned and the other end is roller-supported. In contrast to the separation of laminates in the DCB test, a displacement at the middle of the specimen is used in the ENF simulations.

Modeling of this geometry with FEAMAC, VCCT, and cohesive elements, is identical to the respective DCB simulations, that is the material data employed related to VCCT simulations (critical strain energy release rate $\mathrm{G}_{\text {IIC }}$ reported in Table 1 determines debonding) and for the cohesive surface approach, the tangential debond strength $\sigma_{s}^{0}$ as well as $\mathrm{G}_{\mathrm{IIC}}$ are used to determine the crack initiation and propagation, respectively. For the FEAMAC model, the same debond strength $\sigma_{s}^{0}$ has been used as the bond strength $\sigma_{D B}^{t}$ as expressed in Equation (3). In addition to the $\sigma_{D B}^{t}$, two other parameters critical to interfacial time-dependent behavior of the ECI model are the $\Lambda_{i}$ and $B_{j}$ as reported in Equation (4). To create an interfacial debonding behavior similar to the cohesive and VCCT approaches, a value of $5 \times 10^{-4}$ is selected for $\Lambda_{i}$ while 0.3 is selected for the parameter $B_{j}$.

\section{Comparison of VCCT, Cohesive, and FEAMAC predictions for ENF Test}

To verify the material data presented in Table 1 related to Mode-II delamination, and identify the simulationspecific parameters associated with VCCT, FEAMAC, and cohesive surface approaches, ENF simulations have been conducted for comparison purposes. The reaction force measured at the center of the beam versus the applied displacement is shown in Figure 6. Clearly, all three models start debonding at approximately the same load level, yet the subsequent crack propagation pattern is distinctly different for the FEAMAC model as compared to both the VCCT and cohesive surface models. The latter two models qualitatively behave similarly with a sudden drop followed by a similar propagation pattern after the initiation of the crack. Note, the nature of damage progression in an ENF specimen is sudden and does not follow a slow crack propagation pattern as does the DCB simulation. Due to this sudden nature of crack propagation, it is essential to cognitive of the energies dissipated due to artificial damping introduced for numerical convergence purposes. Both cohesive and VCCT approaches needed significant 


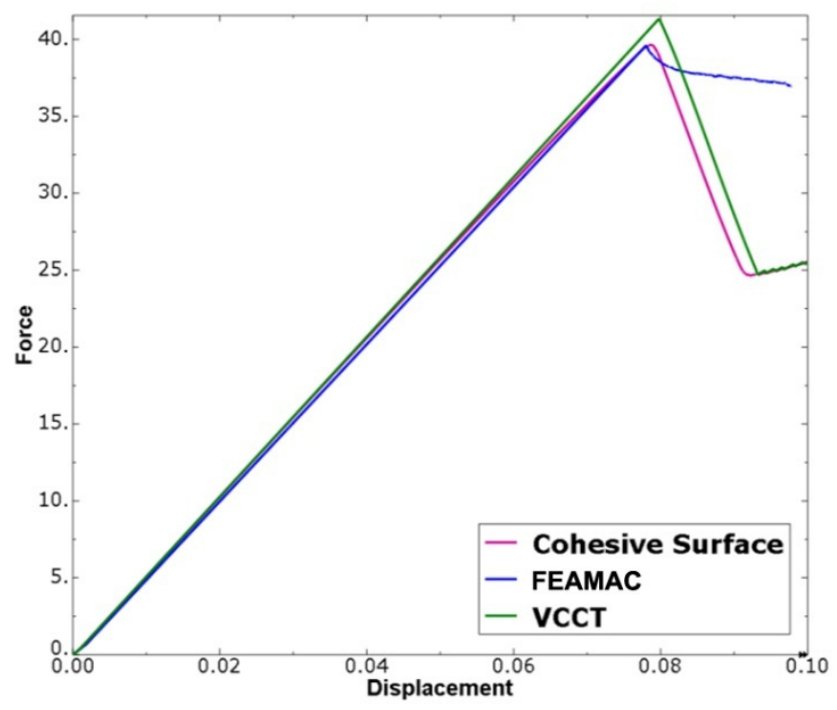

Figure 6.- Reaction forces predicted by VCCT, cohesive, and FEAMAC using adjusted $\mathrm{G}_{\mathrm{c}}$ and $\sigma_{n}^{0}$ for ENF.
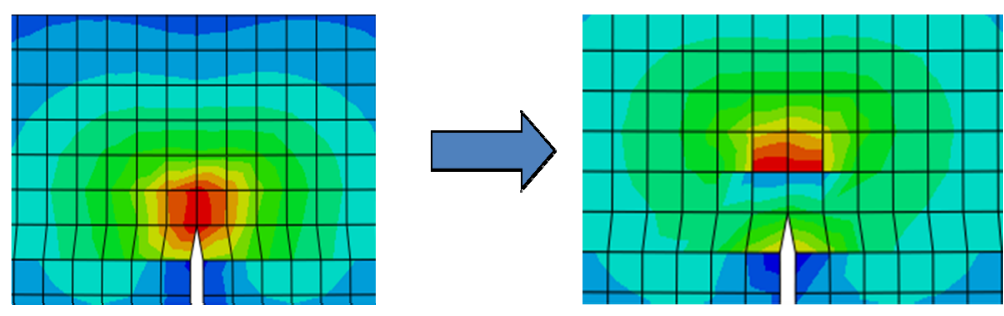

Figure 7.- Initiation and propagation of a crack front between two layers.

damping in order to maintain their numerical stability during simulations; whereas FEAMAC did not require any artificial damping or fine-tuning control parameters associated with the iterative convergence process. Therefore, in addition to execution time, the time needed to condition the solution process, i.e., experiment with numerous control parameters with FEAMAC is minimal, if not nonexistant, as compared to the VCCT and cohesive surface approches.

\section{E. Effect of Mesh Size on FEAMAC}

Finite element simulations of the damage and failure of composite materials have displayed a strong mesh dependency in crack initiation and propagation. This has been reflected on the global load-displacement response as well as the onset, size, and orientation of localized damage zones and crack growth in the composite materials. According to the implementation of FEAMAC, the stiffness of the entire element in a given direction reduces as the crack initiates at an integration point of an element, and progresses between two layers. Due to this stiffness degradation, a large crack opening (compared to a crack tip) is created and the mesh has to be fine enough to represent the propagating crack front (see Fig. 7). This mesh-dependence is common to other continuum damage mechanics approaches which rely upon stiffness degradation as their load redistribution mechanism. Consequently, to simulate the crack propagation as accurately as possible, the mesh must be refined along the possible crack front so that the debonding becomes more of a localized phenomenon, and the loss of element stiffness does not create an unrealistically large crack opening surface which would decrease the crack driving forces. The refined mesh used for FEAMAC is shown in Figure 8(a) together with the mesh used for VCCT simulations in which the mesh can be relatively coarser. 


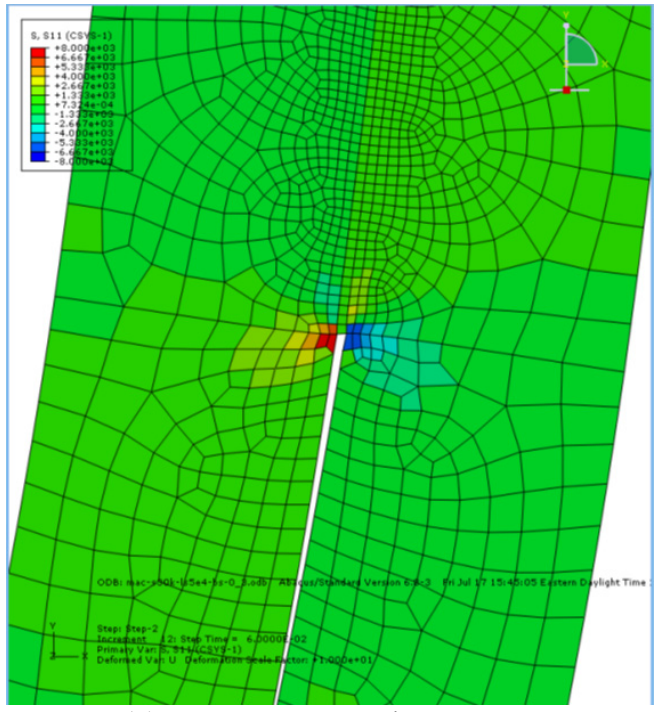

(a). FEAMAC Mesh

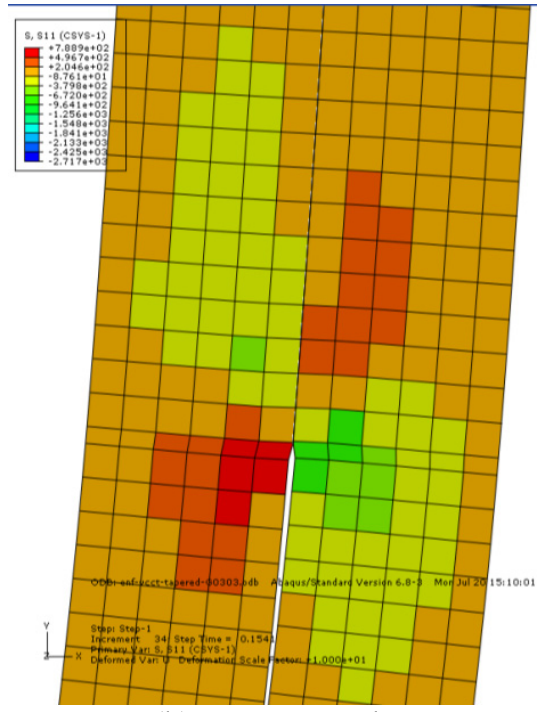

(b). VCCT Mesh

Figure 8.-Mesh refinement needed for FEAMAC compared to VCCT model.

\section{F. Uncoupled Normal and Shear in FEAMAC}

According to the ECI model in Equation (1), debonding can take place due to a normal or shear stress on any given face of a unit-cell. When one of these stresses exceeds the corresponding debonding strength, debonding initiates and the stiffness at an integration point has to degrade for both normal as well as shear. It was found that the current version of FEAMAC has not been implemented to account for this situation properly, in that if propogation of a crack were determined completely by the shear stress, the normal debond strength would still remain as shown in Figure 9(b), whereas conversely, if debonding initiates due to normal stress along the face of a unit-cell, it will still maintain a shear debond strength and the crack would continue to grow due to the normal debonding as in Figure 9(c). To overcome this situation a Hashin's failure criterion has been used to couple the normal and shear stresses on a given face normal to the $\mathrm{x}_{2}$ or $\mathrm{x}_{3}$ direction as expressed in Equation (8):

$$
F_{2}^{t}=\left(\frac{\sigma_{22}}{\sigma_{d b}^{n}}\right)^{2}+\left(\frac{\tau_{21}}{\tau_{d b}^{s}}\right)^{2}+\left(\frac{\tau_{23}}{\tau_{d b}^{s}}\right)^{2} \geq 1 \text { or } F_{3}^{t}=\left(\frac{\sigma_{33}}{\sigma_{d b}^{n}}\right)^{2}+\left(\frac{\tau_{31}}{\tau_{d b}^{s}}\right)^{2}+\left(\frac{\tau_{32}}{\tau_{d b}^{s}}\right)^{2} \geq 1
$$

so that both normal and shear degradation of a given interface intiate simultaneously, if the stresses at the integration point satisfy the condition given in Equation (8). The simulations performed after this implementation of Hashin's criteria displayed the desired effect of combined normal and shear failure as the crack continues to grow in a nonself-similar fashion.

\section{G. Prediction of Crack Path with FEAMAC}

In the previous sections, DCB and ENF simulations have been used to verify the material data for simulations under Mode-I and Mode-II loading conditions. Additionally, these simulations have been used to identify the appropriate simulation-specific conditions such as viscous regularization, mesh size, control parameters related to convergence, etc., for VCCT and cohesive simulations, as well as the $\Lambda_{i}$ and $B_{j}$ parameters for the FEAMAC simulations. In this section, the ECI model available within FEAMAC, with the newly implemented Hashin's criterion for interfacial failure, is used to demonstrate the prediction of crack path, when the crack path is unknown.

To compare the FEAMAC predictions against other available techniques such as XFEM, simulation of a threepoint bend specimen under the plane strain conditions subjected to Mode-I loading, has been selected. The total length of the specimen is taken as 2 in. with a height of 0.4 in. (Ref. 17), and an initial crack length of 0.08 in. was employed as shown in Figure 10. 


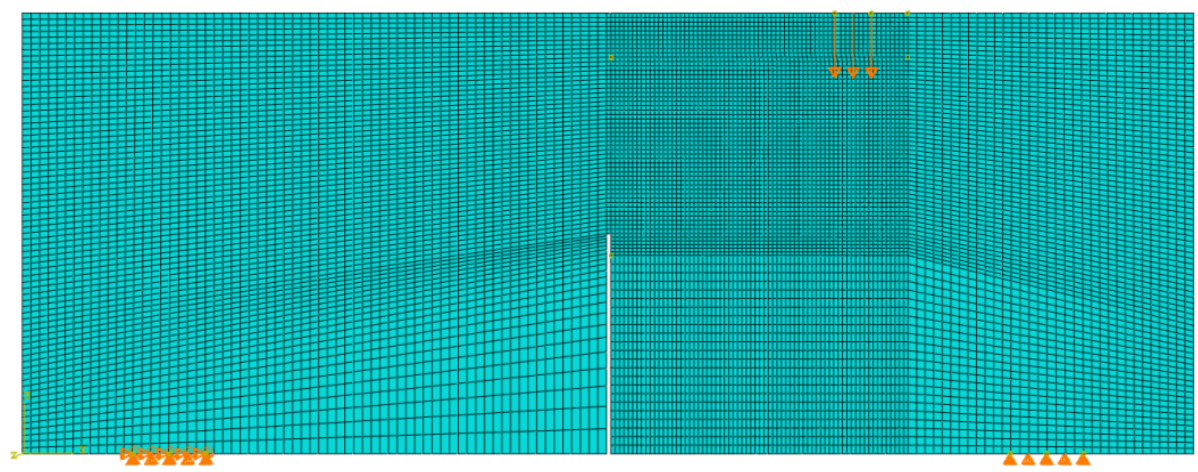

(a) Eccentrically loaded 3-Point Bend Test

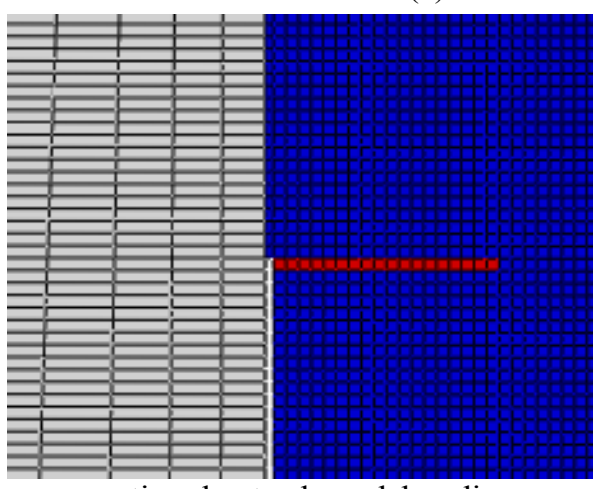

(b) Crack propagation due to shear debonding

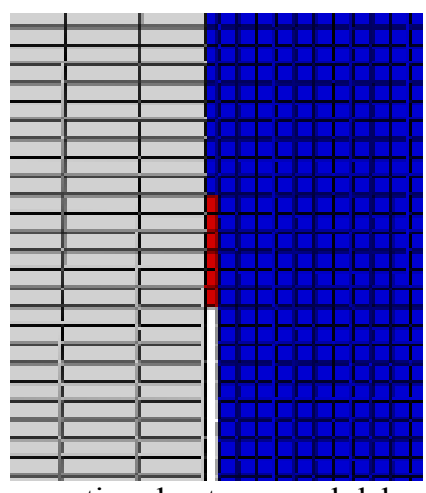

(c) Crack propagation due to normal debonding

Figure 9.-Shear and normal debonding within a 3-point bend specimen.

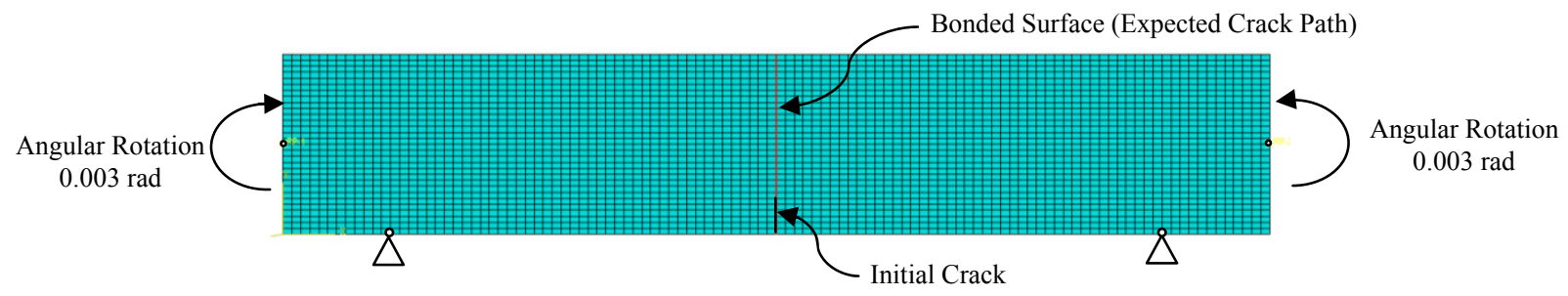

Figure 10.-Three-point bend specimen with initial crack, boundary conditions, and loading.

An angular rotation of 0.003 radians is applied at the center of the left and the right edges of the test specimen, while maintaining kinematic coupling constraints between each center point and the corresponding edge. Since the focus of this research is on the study of applying FEAMAC for predicting crack propagation with monolothic materials, isotropic material properties with damage parameters reported under Table 3 are used for these simulations.

Simulation of the problem with VCCT, FEAMAC, and cohesive surface approaches are very much similar to the simulation of DCB under Mode-I loading using each technique. Unlike VCCT and cohesive approaches, XFEM and FEAMAC do not require a pre-existing crack or any prior knowledge of the crack path. Since the loading is symmetric on the three-point bending specimen, the crack is supposed to follow the expected crack path, as shown in the Figure 10. In the cohesive and VCCT models, this path has to be specified as the prospective crack path and the models will not look for other possible crack directions. However, in the XFEM simulation, crack direction can change based on the specified crack propagation criteria. Any purturbation in the numerical solution process may cause the crack to change its direction, even though the loading, boundary conditions, geometry, and meshing are perfectly symmetrical (Ref. 17). Therefore, to compare the results with the VCCT and cohesive approaches, it is necessary to maintain the symmetry of displacement by constraining the displacements of the left and right edges where the angular displacement is applied. This precaution is necessary for XFEM simulations to force the propagation of the crack in the anticipated direction. In fact, the need to utilize constraint equations to maintain symmetry is a deficiency in the implementation of XFEM, since the crack should have propagated along the path highlighted in Figure 10 without introducing additional constraints. 
TABLE 3.-MATERIAL PROPERTIES USED FOR THREE-POINT BEND SIMULATIONS

\begin{tabular}{|c|c|c|c|c|c|}
\hline $\mathrm{E} / \mathrm{ksi}$ & $v$ & $\mathrm{G}_{\mathrm{IC}} /$ in.-lb/in. $^{2}$ & $\mathrm{G}_{\mathrm{IIC}} /$ in.-lb/in. $^{2}$ & $\mathrm{G}_{\mathrm{IIIC}} / \mathrm{in} .-\mathrm{lb} / \mathrm{in}^{2}$ & $\eta$ \\
\hline 29,000 & 0.3 & 0.571 & 0.571 & 0.571 & 2.284 \\
\hline$\sigma_{n}^{0} / \mathrm{ksi}$ & $\sigma_{s}^{0} / \mathrm{ksi}$ & $\sigma_{t}^{0} / \mathrm{ksi}$ & & & \\
\hline 25.4 & 25.4 & 25.4 & & & \\
\hline \multicolumn{4}{|c|}{ Only for FEAMAC } & \multicolumn{2}{|c|}{ Only for XFEM } \\
\hline$\sigma_{d b}^{n} / \mathrm{ksi}$ & $\sigma_{d b}^{s} / \mathrm{ksi}$ & $\Lambda_{i}$ & $B_{j}$ & \multicolumn{2}{|c|}{ Maximum Principal Stress/ksi } \\
\hline 33.4 & 33.4 & 0.10 & 0.30 & \multicolumn{2}{|c|}{18.9} \\
\hline
\end{tabular}

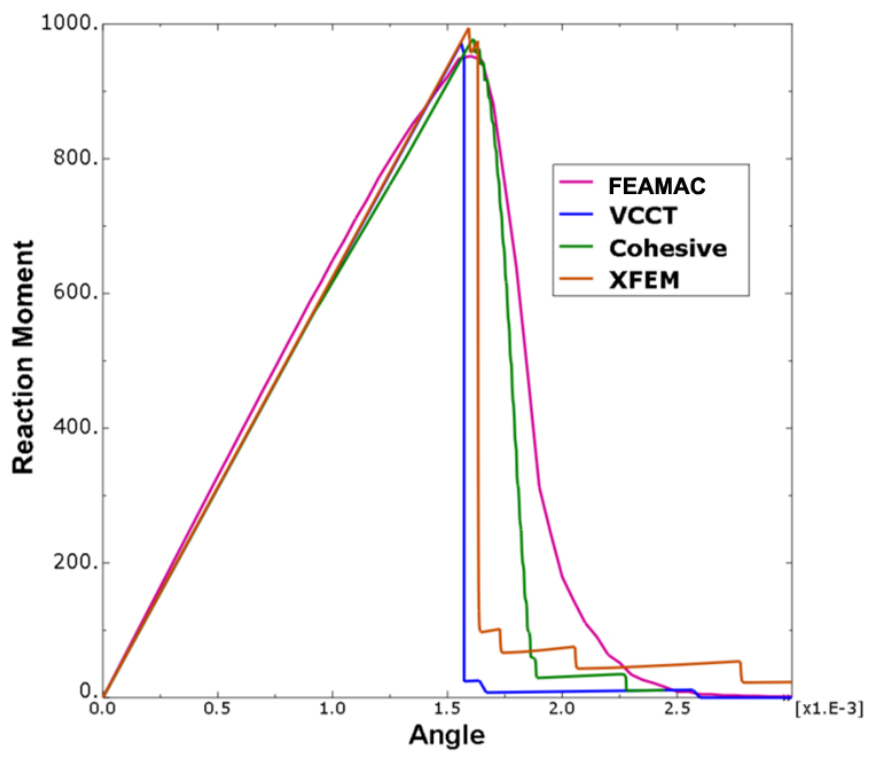

Figure 11.-Reaction moment predicted by FEAMAC, VCCT, Cohesive, and XFEM simulations.

The reaction moment observed at the center point of the right-edge verses the applied angular displacement is plotted in Figure 11 for all considered techniques. Reaction values predicted at the initiation of the crack are similar among all the techniques, but the reaction values observed during the propagation of the crack are somewhat different among the models. Both VCCT and XFEM have sudden crack opening, while cohesive and FEAMAC predict relatively slower crack extension against the applied angular rotation.

As expected, the crack in the VCCT and cohesive models followed the predefined crack path along the center of the specimen (indicated as the bonded surface in Figure 10). Since the symmetric conditions have been enforced during XFEM simulation, the crack continues to grow along the middle of the specimen, similar to the VCCT and cohesive simulations. It is worth mentioning that the addition of such constraint equations to an FEA model can significantly increase the computational time, especially with nonlinear material properties and large-scale structural problems. The displacement discontinuity approach in FEAMAC does not require additional constraints to maintain symmetry, and it was observed that the crack continued along the center similar to the three above techniques. Based on the results reported in Figure 11, it can be concluded that the ability to predict the crack path, and the resultant reaction moment from each technique, have been verified through the simulations with three-point bend specimen. 


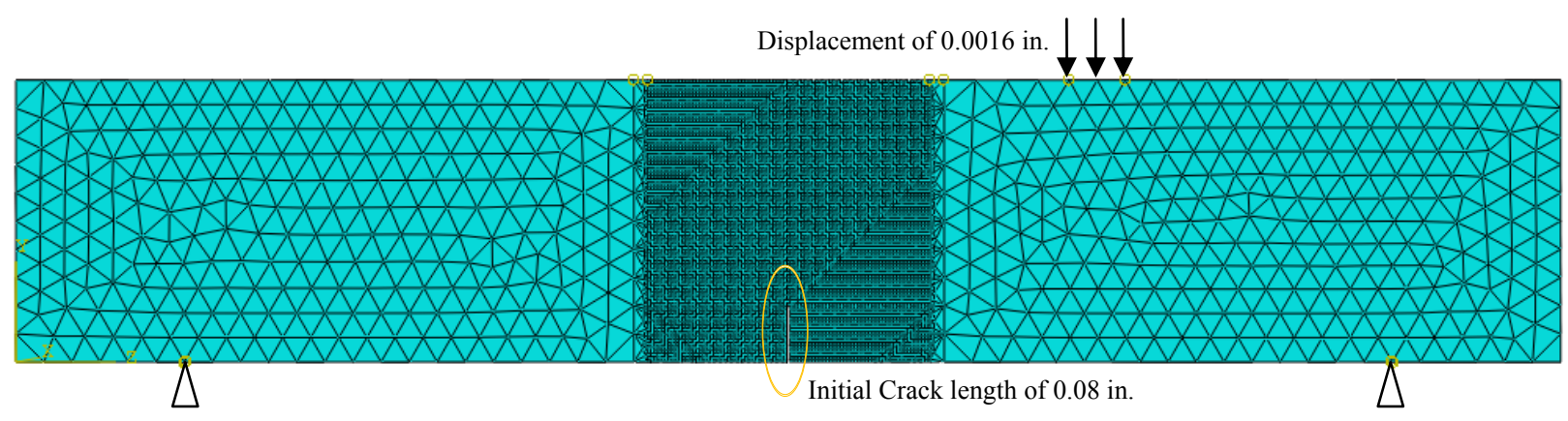

Figure 12.-Eccentrically loaded three-point bend specimen with initial crack, boundary conditions, and loading.

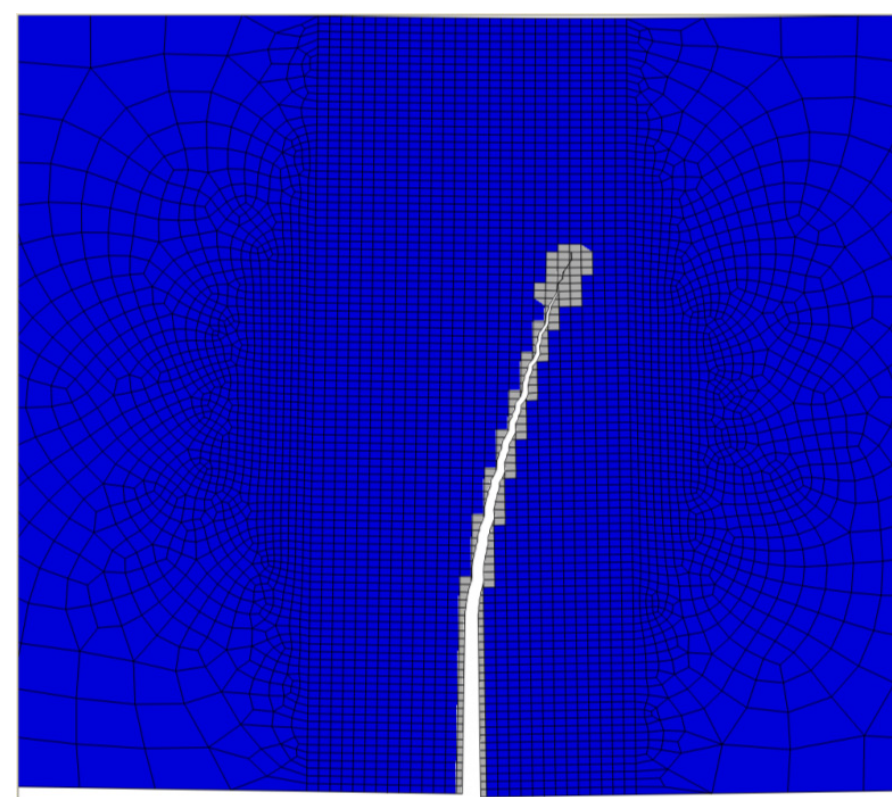

(a) Crack path and plot of failed with XFEM

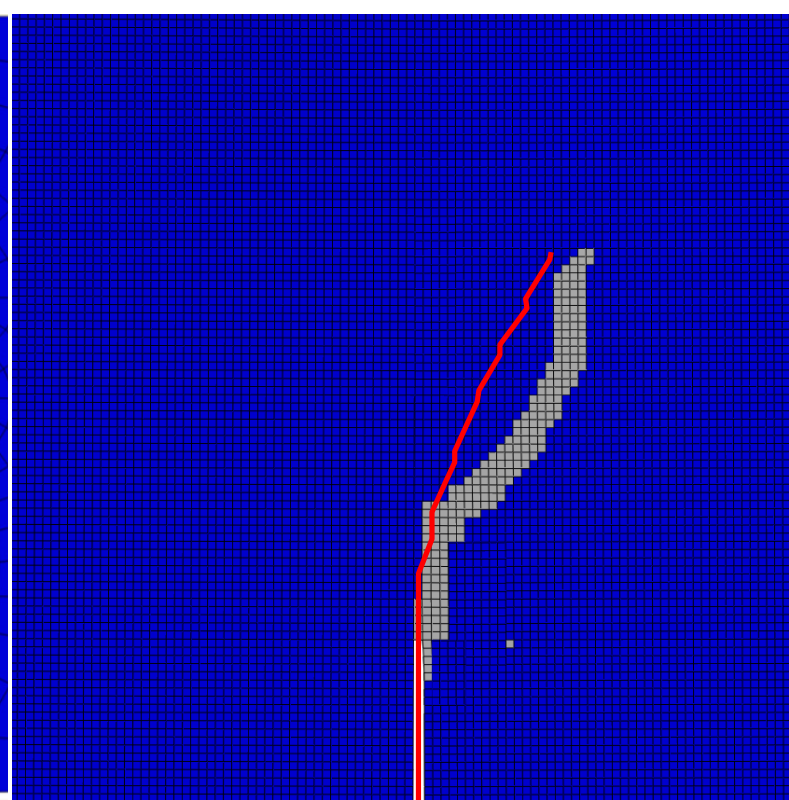

(b) Crack path and failed elements with FEAMAC together with crack predicted by XFEM (in red)

Figure 13.-Comparison of crack path predicted by XFEM and FEAMAC.

The finite element-based VCCT or cohesive element approaches require that the path of the crack be known in advance, whereas FEAMAC and XFEM have the capability to predict where the crack is going to grow without any prior knowledge about the crack path. To demonstrate this capability with FEAMAC, an eccentrically loaded 3-point bend specimen with the same dimensions and initial crack length as in the case described above, is used with displacement and boundary conditions as shown in Figure 12.

Both the XFEM and FEAMAC approaches are used to obtain the crack propagation through finite element simulations. Predicted crack patterns for the given displacement are shown in Figure 13(a) for XFEM and Figure 13(b) for FEAMAC. Results shown in Figure 13(a) display the XFEM predicted crack path (shown in white) together with the partially failed elements as the crack propagates through the beam, whereas Figure 13(b) shows the the XFEM crack path (in red) superimposed on the FEAMAC elements that failed completely during the crack propagation. These two figures demonstrate a fundamental difference between the XFEM and FEAMAC approaches, in that the XFEM approach allows an actual crack surface to be generated by the crack front whereas theFEAMAC crack path is described by the elements that become near zero-stiffness elements to mimic the propagating crack, creating a property discontinuity. Therefore, FEAMAC will have the typical mesh sensitivity exhibited by continuum damage mechanics approaches where no physical discontinuites are present. 
According to these simulation results, both approaches predict the crack path closely at the beginning of the crack propagation, but they deviate as the crack progresses along the specimen. Additionally, FEAMAC tends to fail a number of elements across the width of the crack path whereas XFEM fails only the elements that are directly divided by the propagating crack front. This discrepency could be associated with the debonding parameters utlized, the use of the Hashin failure criteria, and/or mesh sensitivity issues; all of which will be the subject of future work. Selection of an appropriate principal stress value for XFEM simulations has a significant effect on the prediction of the crack path as well as the extent of the the crack for a given displacement. Adequate mesh refinement is another factor to obtain a reliable prediction for crack path with XFEM. Since the entire element fails as the crack progresses, FEAMAC also relies on a finer mesh density to maintain a narrow crack path through the material.

\section{Conclusions}

An extensive comparison of the displacement discontinuity approach in FEAMAC with existing approaches (cohesive elements, the Virtual Crack Closure Technique, and XFEM method) available in Abaqus finite element software has been conducted to evaluate the micromechanics-based approach and identify needed enhancements. As a result of these simulations, issues related to the implementation of FEAMAC as well as conceptual issues such as shear and normal coupling at debonding, have been identified and resolved. During this study, the FEAMAC approach has been used to investigate failure within materials efficiently and to explore the possibility of predicting non-self-similar crack paths. An eccentrically loaded 3-point bend test has been simulated with FEAMAC and the results are similar to XFEM predictions at the beginning of crack initiation, with some deviation from the XFEM predictions as the crack front progresses through the specimen under displacement control.

Based on the experience with finite element based approaches and the micromechanics approach with FEAMAC, it is understood that the micromechanics based FEAMAC approach has far less sensitivity to parameters associated with numerical convergence. Additionally, FEAMAC offers significant advantage over the number of elements used compared to the cohesive approach and hence the computational time required to complete a simulation. This may offer an advantage over established finite element-based approaches in providing efficient and robust design tools for bonded composite joints. Most significantly, FEAMAC appears to have the potential to predict arbitrary crack paths similar to XFEM, whereas the VCCT and cohesive element approaches require predetermined crack paths.

To validate fully the FEAMAC simulation results, it is necessary to compare the predictions with experimental data. In the absence of such data, comparison has been made to an XFEM simulation of an isotropic, eccentricallyloaded, three-point bend specimen. Isotropic material properties where utilized due to the difficulty in estimating a suitable principal stress value for XFEM, which prevented using orthotropic material properties. In contrast FEAMAC simulations need only the debonding strength values that have been verified through DCB and ENF simulations and thus easily applied to orthotropic and composite materials.

\section{References}

1. Bednarcyk, B.A. and Arnold, S.M., "A New Local Debonding Model with Application to the Transverse Tensile and Creep Behavior of Continuously Reinforced Titanium Composites," NASA/TM-2000-210029, 2000.

2. Bednarcyk, B.A. and Arnold, S.M., "Transverse Tensile and Creep Modeling of Continuously Reinforced Titanium Composites with Local Debonding,” International Journal of Solids and Structures 39 (7), 2002, pp. 1987-2017.

3. Bednarcyk, B.A., and Arnold, S.M., MAC/GMC 4.0 User's Manual, NASA/TM-2002-212077, 2002.

4. Krueger, R., "The Virtual Crack Closure Technique: History, Approach and Applications," NASA/CR_-2002211628, 2002.

5. Comanho, P.P. and Davila, C.G., "Mixed-Mode Decohesion Finite Elements for the Simulation of Delamination in Composite Materials," NASA/TM-2002-211737, 2002.

6. Ranatunga, V., Bednarcyk, B.A. and Arnold, S.M., "Modeling Delamination in composites via Continuum Interfacial Displacement Discontinuities," 50th AIAA ASME/ASCE/AHS/ASC SDM Conference, Palm Springs, CA, May, 2009.

7. Moes, N., Dolbow, J., Belytschko, T., “A Finite Element Method for Crack Growth Without Remeshing,” International Journal for Numerical Methods in Engineering, 46(1), 1999, pp. 131-150.

8. Jones, J.P., and Whittier, J.S., "Waves at Flexibly Bonded Interfaces," Journal of Applied Mechanics 34, 1967, pp. $905-909$. 
9. Aboudi, J., "Damage in Composites - Modeling of Imperfect Bonding," Composites Science and Technology 28, 1987, pp. 103-128.

10. Sankurathri, A., Baxter, S. and Pindera, M.J., "The Effect of Fiber Architecture on the Inelastic Response of Metal Matrix Composites with Interfacial and Fiber Damage," in Damage and Interfacial Debonding in Composites, G.Z. Voyiadjis and D.H. Allen (eds.), Elsevier, New York, 1996, pp. 235-257.

11. Achenbach, J.D. and Zhu, H., "Effect of Interfacial Zone on Mechanical Behavior and Failure of FiberReinforced Composites," Journal of the Mechanics and Physics of Solids, 37 (3), 1989, pp. 381-393.

12. Wilt, T.E. and Arnold, S.M., "Micromechanics Analysis Code (MAC) User Guide: Version 2.0," NASA TM 107290, 1996.

13. Needleman, A., "A Continuum Model for Void Nucleation by Inclusion Debonding," Journal of Applied Mechanics 54, 1987, pp. 525-531.

14. Robertson, D.D. and Mall, S., "Micromechanical Analysis of Metal Matrix Composite Laminates with Fiber/Matrix Interfacial Debonding," Composites Engineering 4 (12), 1994, pp. 1257-1274.

15. Song, K., Davila, C.G., and Rose, C.A., "Guidelines and Parameter Selection for the Simulation of Progressive Delamination," Abaqus Users' Conference, Newport, RI, 2008.

16. Rudraraju S., Salvi, A., Garikpati, K., and Waas, A., "In-Plane fracture of laminated fiber reinforced composites with varying fracture resistance: experimental observations and numerical crack propagation simulations," 50th AIAA ASME/ASCE/AHS/ASC SDM Conference, Palm Springs, CA, May, 2009.

17. Dassault Systemes, "Modeling Fracture and Failure with Abaqus," Lowell, MA, 2009. 


\begin{tabular}{|c|c|c|c|c|c|}
\hline \multicolumn{5}{|c|}{ REPORT DOCUMENTATION PAGE } & $\begin{array}{l}\text { Form Approved } \\
\text { OMB No. 0704-0188 }\end{array}$ \\
\hline \multicolumn{6}{|c|}{$\begin{array}{l}\text { The public reporting burden for this collection of information is estimated to average } 1 \text { hour per response, including the time for reviewing instructions, searching existing data sources, gathering and maintaining the } \\
\text { data needed, and completing and reviewing the collection of information. Send comments regarding this burden estimate or any other aspect of this collection of information, including suggestions for reducing this } \\
\text { burden, to Department of Defense, Washington Headquarters Services, Directorate for Information Operations and Reports (07004-0188, } 1215 \text { Jefferson Davis Highway, Suite } 1204 \text {, Arlington, VA } 222202-4302 \text {. } \\
\text { Respondents should be aware that notwithstanding any other provision of law, no person shall be subject to any penalty for failing to comply with a collection of information if it does not display a currently valid OMB } \\
\text { control number. } \\
\text { PLEASE DO NOT RETURN YOUR FORM TO THE ABOVE ADDRESS. }\end{array}$} \\
\hline \multicolumn{2}{|c|}{$\begin{array}{l}\text { 1. REPORT DATE (DD-MM-YYYY) } \\
01-10-2010\end{array}$} & \multicolumn{3}{|c|}{$\begin{array}{l}\text { 2. REPORT TYPE } \\
\text { Technical Memorandum }\end{array}$} & 3. DATES COVERED (From - To) \\
\hline \multirow{3}{*}{\multicolumn{5}{|c|}{$\begin{array}{l}\text { 4. TITLE AND SUBTITLE } \\
\text { Modeling Progressive Damage Using Local Displacement Discontinuities Within the } \\
\text { FEAMAC Multiscale Modeling Framework }\end{array}$}} & 5a. CONTRACT NUMBER \\
\hline & & & & & 5b. GRANT NUMBER \\
\hline & & & & & 5c. PROGRAM ELEMENT NUMBER \\
\hline \multirow{3}{*}{\multicolumn{5}{|c|}{$\begin{array}{l}\text { 6. AUTHOR(S) } \\
\text { Ranatunga, Vipul; Bednarcyk, Brett, A.; Arnold, Steven, M. }\end{array}$}} & 5d. PROJECT NUMBER \\
\hline & & & & & 5e. TASK NUMBER \\
\hline & & & & & $\begin{array}{l}\text { 5f. WORK UNIT NUMBER } \\
\text { WBS } 645846.02 .07 .03 .13\end{array}$ \\
\hline \multicolumn{5}{|c|}{$\begin{array}{l}\text { 7. PERFORMING ORGANIZATION NAME(S) AND ADDRESS(ES) } \\
\text { National Aeronautics and Space Administration } \\
\text { John H. Glenn Research Center at Lewis Field } \\
\text { Cleveland, Ohio 44135-3191 }\end{array}$} & $\begin{array}{l}\text { 8. PERFORMING ORGANIZATION } \\
\text { REPORT NUMBER } \\
\text { E-17454 }\end{array}$ \\
\hline \multirow{2}{*}{\multicolumn{5}{|c|}{$\begin{array}{l}\text { 9. SPONSORING/MONITORING AGENCY NAME(S) AND ADDRESS(ES) } \\
\text { National Aeronautics and Space Administration } \\
\text { Washington, DC 20546-0001 }\end{array}$}} & $\begin{array}{l}\text { 10. SPONSORING/MONITOR'S } \\
\text { ACRONYM(S) } \\
\text { NASA }\end{array}$ \\
\hline & & & & & $\begin{array}{l}\text { 11. SPONSORING/MONITORING } \\
\text { REPORT NUMBER } \\
\text { NASA/TM-2010-216825 }\end{array}$ \\
\hline \multicolumn{6}{|c|}{$\begin{array}{l}\text { 12. DISTRIBUTION/AVAILABILITY STATEMENT } \\
\text { Unclassified-Unlimited } \\
\text { Subject Category: } 39 \\
\text { Available electronically at http://gltrs.grc.nasa.gov } \\
\text { This publication is available from the NASA Center for AeroSpace Information, 443-757-5802 }\end{array}$} \\
\hline \multicolumn{6}{|c|}{ 13. SUPPLEMENTARY NOTES } \\
\hline \multicolumn{6}{|c|}{$\begin{array}{l}\text { 14. ABSTRACT } \\
\text { A method for performing progressive damage modeling in composite materials and structures based on continuum level interfacial } \\
\text { displacement discontinuities is presented. The proposed method enables the exponential evolution of the interfacial compliance, resulting in } \\
\text { unloading of the tractions at the interface after delamination or failure occurs. In this paper, the proposed continuum displacement } \\
\text { discontinuity model has been used to simulate failure within both isotropic and orthotropic materials efficiently and to explore the possibility } \\
\text { of predicting the crack path, therein. Simulation results obtained from Mode-I and Mode-II fracture compare the proposed approach with the } \\
\text { cohesive element approach and Virtual Crack Closure Techniques (VCCT) available within the ABAQUS (ABAQUS, Inc.) finite element } \\
\text { software. Furthermore, an eccentrically loaded 3-point bend test has been simulated with the displacement discontinuity model, and the } \\
\text { resulting crack path prediction has been compared with a prediction based on the extended finite element model (XFEM) approach. }\end{array}$} \\
\hline \multicolumn{6}{|c|}{$\begin{array}{l}\text { 15. SUBJECT TERMS } \\
\text { Advanced composites; Structural systems; High temperature; FEAMAC }\end{array}$} \\
\hline \multicolumn{3}{|c|}{ 16. SECURITY CLASSIFICATION OF: } & $\begin{array}{l}\text { 17. LIMITATION OF } \\
\text { ABSTRACT }\end{array}$ & $\begin{array}{l}\text { 18. NUMBER } \\
\text { OF }\end{array}$ & $\begin{array}{l}\text { 19a. NAME OF RESPONSIBLE PERSON } \\
\text { STI Help Desk (email:help@sti.nasa.gov) }\end{array}$ \\
\hline $\begin{array}{l}\text { a. REPORT } \\
\text { U }\end{array}$ & $\begin{array}{l}\text { b. ABSTRACT } \\
\text { U }\end{array}$ & $\begin{array}{l}\text { C. THIS } \\
\text { PAGE } \\
\text { U }\end{array}$ & UU & $\begin{array}{l}\text { PAGES } \\
19\end{array}$ & $\begin{array}{l}\text { 19b. TELEPHONE NUMBER (include area code) } \\
443-757-5802\end{array}$ \\
\hline
\end{tabular}



